Van Duyne, C. M. \& Havel, R. J. (1959). Proc. Soc. exp. Biol. Med. roz, 599.

Van Duyne, C. M., Parker, H. R., Havel, R. J. \& Holm, L. W. (r960). Am. J. Physiol. r99, 987.

Wasserman, F. (1965). In Handbook of Physiology. Section 5. Adipose Tissue. [A. E. Renold and G. F. Cahill, editors.] Washington DC: American Physiological Society.

Widdowson, E. M. (1950). Nature, Lond. 166, 626.

Widdowson, E. M. \& Spray, C. M. (r95I). Archs Dis. Childh. 26, 205.

\title{
The starving newborn baby
}

\section{By A. W. Wilkinson, Institute of Child Health, Hospital for Sick Children, London, $W C \mathrm{I}$}

In the newborn baby starvation implies the failure to consume and absorb enough calories and other materials to satisfy fully the requirements for growth as well as maintenance. If surgical treatment is necessary, involving the infliction of injury, these basic requirements are increased in order to provide for the resulting larger energy consumption and for the inflammatory response. Although the starving subject heals satisfactorily at any age, especially when the pre-operative nutritional state is good, this is achieved at the expense of the endogenous provision of the necessary materials. Such healing occurs normally and uneventfully in babies born as much as 8 weeks prematurely, who may weigh less than $2 \mathrm{~kg}$, or who have been starved almost completely for up to ro days or more, and may have lost a quarter of their stated birth weight.

Pure starvation is seldom seen in surgical patients because they usually have some form of intestinal obstruction, which by vomiting causes the loss of upper gastrointestinal secretions. It must also be emphasized that there is almost always some uncertainty about the stated birth weight, about the quantity and composition of the material which has been vomited, the amount of milk which has been consumed and how much of it has been retained.

Some degree of starvation occurs even in normal newly born babies in the widely varying period of time between the ligation of the umbilical cord and the starting of milk feeds. This delay occurs even when an abundant supply of expressed human breast milk is regularly offered to the baby from a few hours after birth, and appears to be due to the failure of the baby to consume milk rather than to the deficient production of milk by the mother (Wilkinson, Stevens \& Hughes, 1962). This delay is increased by foetal distress and after difficult or prolonged labour. During this sort of starvation immediately after birth the output of nitrogen, potassium and sodium in the urine is small, partly because so little urine is formed, perhaps only to $\mathrm{ml}$ per $\mathrm{kg}$ per $24 \mathrm{~h}$. When the volume of urine rises after the intake of milk begins there is usually an increase in the output of nitrogen for a few days although the output of potassium and sodium fall. Starvation of this kind immediately after birth is accompanied by a loss of weight which varies a good deal and is related more closely to the birth weight of the baby than to factors such as foetal distress (Fig. I). 


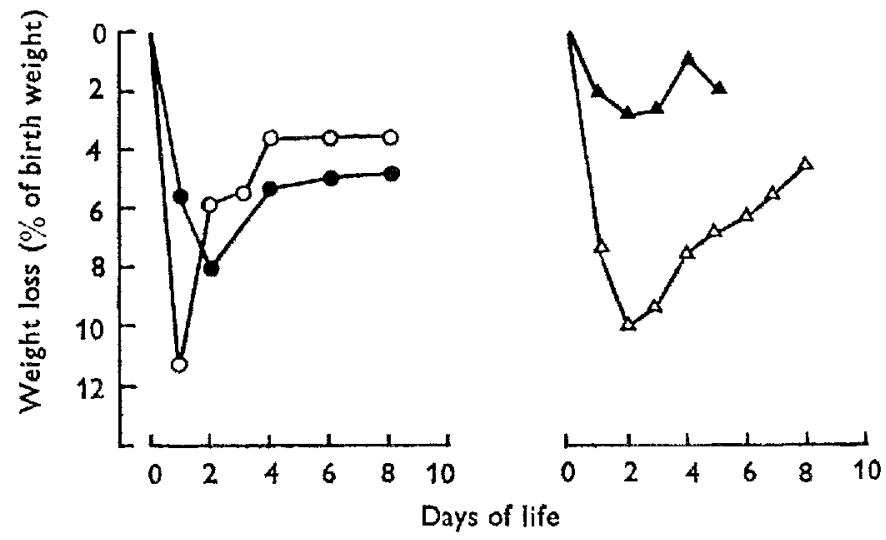

Fig. I. Neonatal starvation. Weight loss expressed as a percentage of birth weight. On the left to show the difference in mean weight of two groups each of five babies with $(-)$ and without $(\mathrm{O}-\mathrm{O})$ foetal distress; on the right two groups each of four babies who weighed either less than $2 \mathrm{~kg}(\mathbf{A}-\mathbf{A})$ or more than $3.5 \mathrm{~kg}(\Delta-\Delta)$.

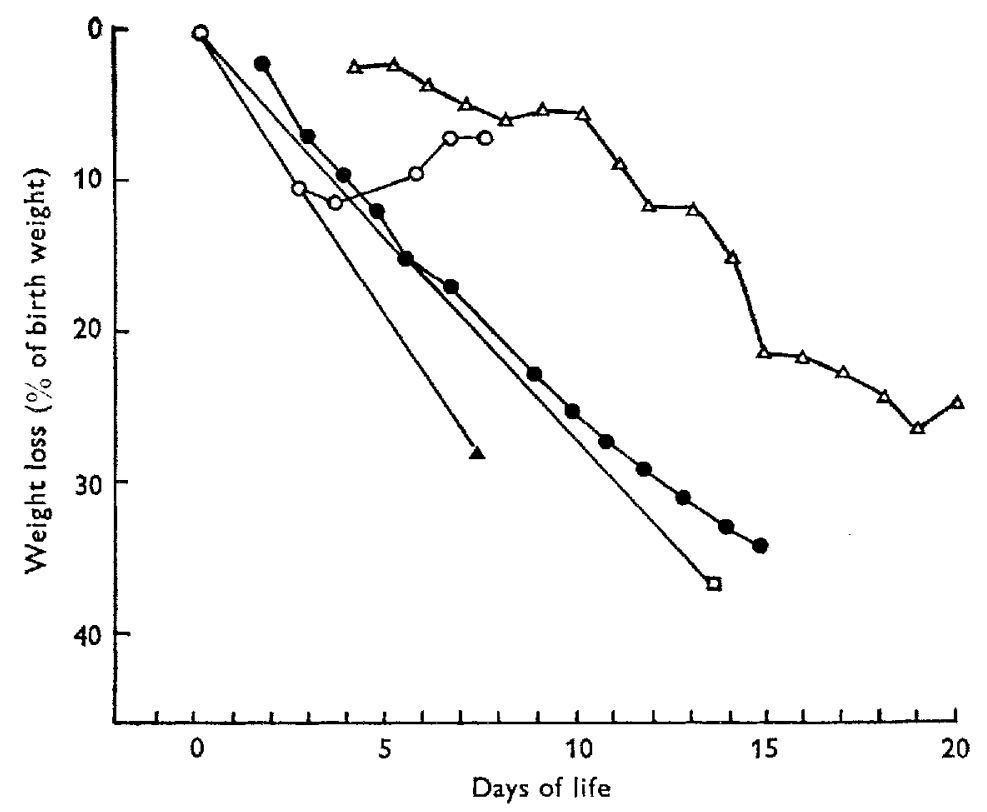

Fig. 2. Neonatal starvation. Weight loss expressed as a percentage of birth weight. $\bigcirc-0$, normal baby, birth weight $3.78 \mathrm{~kg}$, who took only $31 \mathrm{r} \mathrm{ml}$ expressed breast milk in first 2 days (less than $0.1 \%$ body-weight) and $15 \mathrm{ml}$ on $3 \mathrm{rd}$ day, lost $10.75 \%$ of birth weight in 3 days; - - mongol, $2 \cdot 87 \mathrm{~kg}$ on admission on and day of life, oesophageal atresia with tracheo-oesophageal fistula and severe multiple cardiac anomalies which were technically untreatable, no food or fluid, died on 15 th day after losing $34 \%$ of weight on admission; the rate of weight loss declined gradually in a way similar to that shown by Benedict's (I9I5) subject Levanzin; $\Delta-\triangle$, male, birth weight $3.08 \mathrm{~kg}$, admitted on 3 rd day of life with mucoviscidosis and jejunal atresia. Starvation in spite of almost continuous intravenous infusion until death from peritonitis and recurrent intestinal obstruction on 20 th day. Total calorie intake never reached $50 \mathrm{kcal} /$ day. No potassium or protein given until I 7 th day. $\mathbf{A}-\mathbf{A}$, male, birth weight $2 \cdot 8 \mathrm{I} \mathrm{kg}$; duodenal atresia; admitted on 8 th day of life having lost $28 \%$ of stated birth weight; surviving after operative treatment. $\square-\square$, male, birth weight $3.85 \mathrm{~kg}$; duodenal atresia; admitted I 4 th day of life having lost $37 \%$ of stated birth weight; surviving after operative treatment. 
Evidence from balance studies suggests that, as in the adult, much of this weight loss is due to the loss of water which is derived from both extracellular and intracellular fractions of the total body water. Less than $10 \%$ of the original body protein is catabolized but up to $30 \%$ or more of the fat (Hughes, Stevens $\&$ Wilkinson, I964).

Starvation is much more severe and prolonged in babies who have been born with atresias and other anomalies of the alimentary tract. Although starvation before operation is unavoidable there is usually no reason why it should continue after operation. Loss of weight is very variable in rate and degree but it is easy to measure accurately and provided it is carefully interpreted it may be a useful clinical index of starvation (Fig. 2).

In the neonate, just as later in life, starvation causes a disturbance of chemical equilibrium with a base deficit of up to $10-15$ m-equiv. $/ 1$; this is exaggerated only a little by oesophageal atresia, in which only saliva is lost from the blind upper pouch of the oesophagus. In duodenal atresia however the repeated vomiting of accumulated gastric secretions for several days causes so much loss of hydrogen ions that there is a base excess of $1^{1} \mathrm{I}_{5} \mathrm{~m}$-equiv./1. or more. Such disturbances can be corrected rapidly by the intravenous infusion of solutions containing sodium bicarbonate or ammonium or potassium chloride, and more slowly simply by feeding the baby with undiluted human milk from $24 \mathrm{~h}$ after surgical relief of the obstruction.

It is difficult to establish the degree of starvation which has occurred before a baby is admitted to hospital, because the stated birth weight may be inaccurate, and it impossible to estimate how much ingested milk and gastro-intestinal secretions have been lost by vomiting. After operation, at least in boys, the losses can be collected and measured and by the use of a gastrostomy, jejunostomy or ileostomy a satisfactory intake of milk can be achieved and materials aspirated from higher up the alimentary tract can be returned below the original level of obstruction (Wilkinson, Hughes \& Stevens, r965; Hughes, Stevens, Toms \& Wilkinson, 1965). In this way the absolute loss from the body of large quantities of sodium, potassium and water can be prevented; in ro days the loss of sodium in fluid aspirated from the stomach of a baby with duodenal atresia may be equivalent to the total body content.

Human milk is the ideal food for the newborn baby especially after operation; its lower total osmolality compared with cow's milk is an advantage in a baby who may be suffering from water lack as well as starvation. The amount of milk which can be safely administered by tube, even into the jejunum, may be limited by delay in emptying of the intestine or by regurgitation past the tube into the duodenum and stomach (Fig. 3). Even when an adequate intake of milk is achieved by oral or tube feeding the tissue catabolism associated with the injury of operation, or severe infection due to complications, such as peritonitis or pyopneumothorax due to leakage from an anastomosis, may prevent or delay the achievement of positive metabolic balance which is the basis for growth and one of the principal objects of treatment. The degree to which oral feeds of whole milk can be replaced by the intravenous infusion of mixtures of solutions of amino acids derived from hydrolysed milk casein, fructose or glucose, alcohol and emulsions of soya-bean oil 

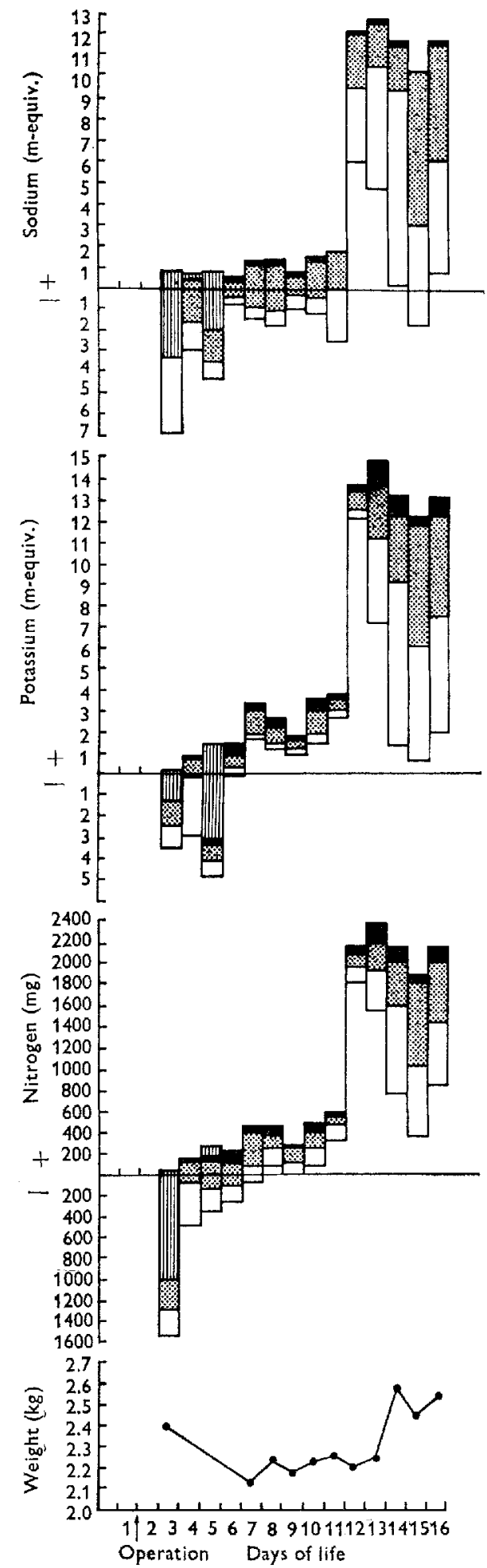

Fig. 3. Balances of sodium, potassium and nitrogen, and body-weight in a male baby, birth weight $2.5 \mathrm{~kg}$ with a duodenal atresia necessitating duodenojejunostomy on the and day of life. Intake is plotted up from the baseline. Output is plotted down from the top of the intake line. iti , loss by gastric aspiration; $\mathbf{Q}$, loss in faeces; 圈, material extracted from napkin or bedding; $\square$, loss in urine. For 9 days after operation intake of expressed breast milk through trans-anastomotic tube was limited by regurgitation into proximal duodenum and stomach. Positive balance was achieved for nitrogen on 8th day, potassium on 5 th day and sodium only on roth day when intake was increased and changed to halfcream national dried milk. 
(Schuberth, r964), is limited by the rate at which these substances, especially the oil, can be cleared from the blood stream and utilized, and by the complications of prolonged or repeated intravenous infusions. Parenteral feeding is probably most useful when a large part of the small intestine has been destroyed before birth by infarction in a volvulus or strangulated obstruction, especially if much of the ileum is affected. It seems likely that at least 25 to $30 \mathrm{~cm}$ of small intestine, out of a normal length at birth of about $25^{\circ}$ to $35^{\circ} \mathrm{cm}$, is necessary for survival and that the terminal ileum is the most important segment to preserve. When the length of the small intestine is much reduced unmodified human or cow's milk passes from mouth to anus very rapidly, sometimes in only ro min. It is then necessary to modify the milk, first by removing as much fat as possible and then to predigest it by the addition of Benger's food and fortify it with readily absorbed materials such as amino acids and glucose so that in its short contact with the intestinal mucosa as much as possible can be absorbed. The substitution of a medium-chain triglyceride preparation for the milk fat (Winawer, Broitman, Wolochow, Osborne \& Janochek, I966; Wilkinson, 1968 ) will increase the calorie content of the feeds more safely than the addition of carbohydrate.

Diarrhoea due to disaccharide intolerance or to infection may also cause such rapid transit of the feeds through the bowel that digestion and absorption are impaired, large amounts of intestinal secretions are lost and starvation results (Fig. 4). Breast milk may be treated with lactase. Galactomin (Trufood) in which glucose or fructose is the carbohydrate and which is available with a full or reduced fat content is a good substitute for milk (Clayton, Arthur \& Francis, 1966), but it is

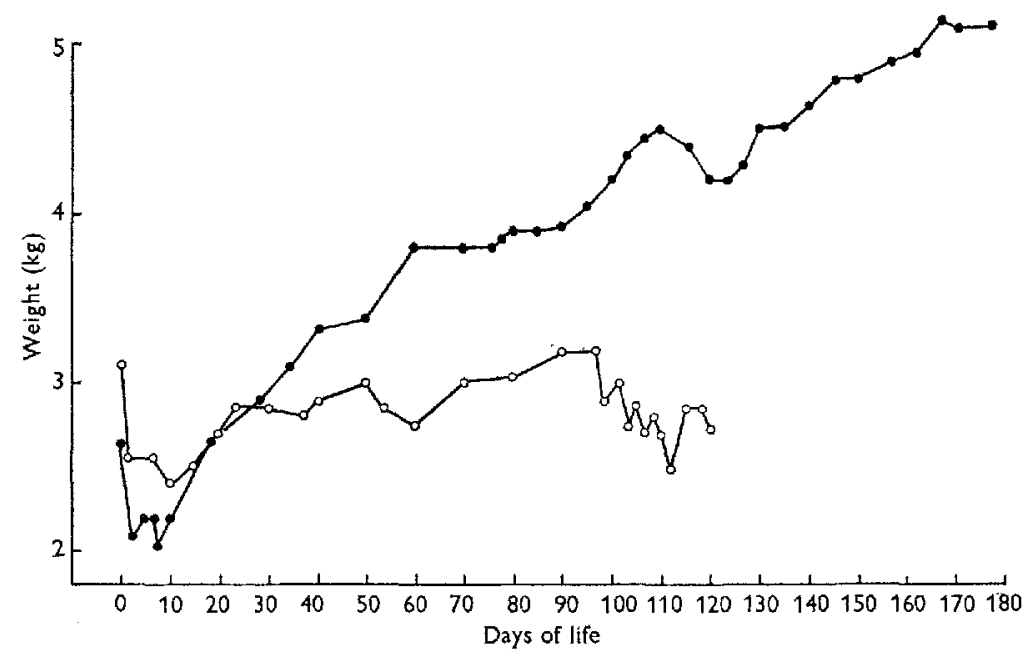

Fig. 4. Neonatal starvation. Weight changes after resection of small intestine. - -1 , neonatal resection of small intestine for atresia, $45 \mathrm{~cm}$ remained; dissacharide intolerance; medium-chain triglycerides added to feeds on $7 \mathrm{Ist}$ day; surviving aged 2 years. $\mathrm{O}-\mathrm{O}$, neonatal resection of small intestine for atresia, $60 \mathrm{~cm}$ remained; peritonitis, disaccharide intolerance, repeated enteritis; almost regained birth weight after 90 days; died. 
essential to give also a complete vitamin supplement and supplements of the elements which are deficient in galactomin if it is to be used for more than a few weeks. Although disaccharide intolerance causes severe diarrhoea it may not last long and cow's milk feeds can be cautiously resumed. The control of infection in the bowel is often difficult because the causal organism is not susceptible to available chemotherapy and may even be encouraged by it.

\section{REFERENCES}

Benedict, F. G. (19 15). A Study of Prolonged Fasting. Washington: Carnegie Institute of Washington. Clayton, B. E., Arthur, A. B. \& Francis, D. E. M. (1966). Br. med. \%. ii, 679.

Hughes, E. A., Stevens, L. H., Toms, D. A. \& Wilkinson, A. W. (1965). Br. 7. Surg. 52, 403.

Hughes, E. A. Stevens, L. H. \& Wilkinson, A. W. (1964). Archs Dis. Childh. 39, 598.

Schuberth, O. (1964). Acta chir. scand. Suppl. 325, 43 .

Wilkinson, A. W. (1968). Some Effects of Extensive Intestinal Resection in Childhood. Symposium on Intestinal Absorption and Malabsorption held in Zurich in November, 1967. Zurich: Karger. (In the Press.)

Wilkinson, A. W., Hughes, E. A. \& Stevens, L. H. (r965). Br. J. Surg. 52, 408.

Wilkinson, A. W., Stevens, I. H. \& Hughes, F, A. (I962). Lancet i, 983 .

Winawer, S. J., Broitman, S. A., Wolochow, D. A., Osborne, M. P. \& Janochek, N. (1 966). New Engl. f. $M e d .274,72$.

\section{Feeding the newborn baby}

By Pamela A. Davies, Institute of Child Health, Hammersmith Hospital, London, $W_{\mathrm{I} 2}$

A steady decline in breast-feeding and increasing sophistication of artificial feeding is to some extent a consequence of the emancipation of women. Approximately $80 \%$ of the nation's babies are now bottle-fed, their mothers influenced, subconsciously no doubt, in their choice of food and even method by the large-scale advertizing of the commercial baby food caucuses. Striking differences in mortality between breast- and bottle-fed no longer exist in this country but we should remind ourselves of other aspects of this trend, of importance alike to the well-grown mature infant and the baby of low birth weight. Discussion will be confined to the physical properties of human milk vis-a-vis cow's milk, and will not include the psychological advantage to mother and child, real though it may be, of the act of breast feeding.

Widdowson (I963) has stressed the successful integration of growth with renal function occurring for each species when maternal milk is available. This fine adjustment of mineral balance and kidney function is of particular importance in the first weeks of life, when the fits, thought to be hypocalcaemic, of 'neonatal tetany' may occur in the artificially fed. 'This complex metabolic upset may be initiated in part by the higher phosphate load of cow's milk which is excreted with difficulty by the infant kidney (Bakwin, 1939). Lactose is known to increase the retention of dietary calcium (Duncan, I 955), and the higher content of lactose in 